http://jmscr.igmpublication.org/home/

ISSN (e)-2347-176x ISSN (p) 2455-0450

crossref DOI: https://dx.doi.org/10.18535/jmscr/v7i11.177

Journal Of Medical Science And Clinical Research

IGM Publication

An official Publication of IGM Publication

\title{
Mortality and morbidity profile of neonates admitted to Special neonatal care unit
}

\author{
Authors \\ Ankur Dharmani $\mathrm{MD}^{1}$, Sonia Kashyap $\mathrm{MD}^{2^{*}}$ \\ ${ }^{1}$ Pediatrician, Regional hospital, Bilaspur H.P \\ ${ }^{2 *}$ Internal Medicine (Medical Specialist), DDU, Shimla, HP \\ *Corresponding Author \\ Sonia Kashyap MD
}

\begin{abstract}
Introduction: The neonatal period ( 0 to 28 days of life) has been the most critical period of life because of the various problems associated with it. Quite a few studies in India have described in detail the morbidity profile of tertiary care NICUs.

Materials and Method: It was an observational study done at Regional hospital Bilaspur, all neonates admitted in SNCU between 2015 to 2019 were included in the study.

Result: A total of 1833 neonates were admitted during the study period, Neonatal jaundice was found to be the most common cause of admission 834 (45.4\%), Other prominent causes were sepsis 242 (13.2\%), birth asphyxia 125 (6.8\%), meconium aspiration syndrome 103 (5.6\%).

Conclusion: Our study shows that neonatal jaundice birth asphyxia and sepsis are the commonest causes of admission.

Keywords: Special neonatal care unit, mortality and morbidity profile.
\end{abstract}

\section{Introduction}

Evidence from relevant literature has shown enormous global progress in the care of newborns during the past 2-3 decades especially in the resource rich settings ${ }^{[1,2]}$. This progress is reflected in the considerable improvement in the survival rate of newborn babies and a better prognosis among survivals in the technically advanced nations ${ }^{[1,2]}$. The reverse is the case in most developing countries where neonatal morbidity such as NNS, LBW, SBA, NNJ, prematurity still remain a major medical problem $^{[3-7]}$. The survival of very preterm in such environments is a major concern for paediatricians caring for the newborns. The neonatal period ( 0 to
28 days of life) has been the most critical period of life because of the various problems associated with it $^{[7]}$. A large majority of newborns may not experience serious problems/difficulties and may require only minimal care by their mothers with little supervision of health workers.

Quite a few studies in India have described in detail the morbidity profile of tertiary care NICUs. However, there are few clinical studies to show the morbidity and mortality profile of SNCUs. The neonatal morbidity profile also had a paradigm shift over the past two decades, as the primary cause of neonatal mortality is now prematurity and associated complications, unlikely birth asphyxia and neonatal sepsis, which 
constituted the major chunk of neonatal mortality few decades before. Hence, it is high time, a clinical study should be performed in a secondary care NICU to reveal the true picture of neonatal morbidity and mortality in community by avoiding referral bias, which is a major shortcoming of clinical studies from tertiary care units.

\section{Materials and Method}

It was an observational study done at Regional hospital Bilaspur catering rural area population of Bilaspur, surrounding areas of Mandi, Hamirpur and Solan districts.

This government hospital provides maternity services in the city, in addition to high percentage of referral of high-risk pregnancies and sick newborns from other peripheral hospitals. The medical files of the neonates were retrospectively reviewed.

All neonates admitted in SNCU between 2015 to 2019 were included in the study. Neonates taken against medical advice and those referred to tertiary care centers were excluded from the analysis. Neonatal infections were diagnosed clinically aided with appropriate tests, which include sepsis screen, blood culture, chest radiograph, and cerebrospinal fluid analysis. Ethical clearance from pediatric department of concerned hospital.

\section{Result}

A total of 1833 neonates were admitted during the study period (Table no. 1). Total male babies were 1072 (58\%) and female babies were 762 (41.5\%). Out of total $1380(75.2 \%)$ were in bourn and 453 (24.7\%) were out born. 580 (31.6\%) new bourns were pre term and $1256(68.5 \%)$ were term babies. Significantly higher number of inborn babies were admitted compared to out born babies.

Neonatal jaundice was found to be the most common cause of admission 834 (45.4\%), Other prominent causes were sepsis $242(13.2 \%)$, birth asphyxia 125 (6.8\%), meconium aspiration syndrome 103 (5.6\%) (Table no 2).

Most common reason for neonatal death was Sepsis/Pneumonia /Meningitis, 11 (0.6\%), other most common causes for neonatal death was prematurity $8(0.4 \%)$, HIE/Moderate-severe birth Asphyxia and others 7 (0.38\%) (Table no. 3).

Table no. 1: Admissions in special neonatal care unit

\begin{tabular}{|c|c|c|c|c|c|c|}
\hline & & 2015 & 2016 & 2017 & 2018 & 2019 (till may) \\
\hline \multicolumn{2}{|l|}{ Admission in the unit } & 196 & 394 & 460 & 608 & 175 \\
\hline \multicolumn{2}{|l|}{ Male } & 117 & 235 & 271 & 354 & 95 \\
\hline \multicolumn{2}{|l|}{ Female } & 79 & 159 & 180 & 254 & 90 \\
\hline \multirow{4}{*}{$\begin{array}{l}\text { Birth weight of the } \\
\text { baby at the time of } \\
\text { admission }\end{array}$} & $\geq 2500 \mathrm{gm}$ & 98 & 226 & 286 & 421 & 110 \\
\hline & $1500-2499 \mathrm{gm}$ & 82 & 154 & 149 & 163 & 61 \\
\hline & $1000-1499 \mathrm{gm}$ & 15 & 14 & 19 & 22 & 4 \\
\hline & $<1000 \mathrm{gm}$ & 1 & 1 & 7 & 3 & 0 \\
\hline \multirow[t]{3}{*}{ Gestation } & $>37$ weeks & 122 & 269 & 319 & 432 & 114 \\
\hline & 34-37 weeks & 55 & 90 & 109 & 141 & 56 \\
\hline & $<34$ weeks & 19 & 36 & 33 & 36 & 5 \\
\hline
\end{tabular}

Table no. 2 Morbidity profile

\begin{tabular}{|l|c|c|c|c|c|}
\hline & $\mathbf{2 0 1 5}$ & $\mathbf{2 0 1 6}$ & $\mathbf{2 0 1 7}$ & $\mathbf{2 0 1 8}$ & $\mathbf{2 0 1 9}$ (till may) \\
\hline Respiratory distress syndrome & 9 & 8 & 15 & 21 & 3 \\
\hline Meconium aspiration syndrome & 9 & 24 & 32 & 33 & 5 \\
\hline Other causes of respiratory distress & 9 & 7 & 20 & 50 & 20 \\
\hline HIE/Moderate-severe birth Asphyxia & $1 / 26$ & $7 / 26$ & $3 / 27$ & $3 / 40$ & $0 / 6$ \\
\hline Sepsis/Pneumonia /Meningitis & $28 / 4 / 0$ & $61 / 23 / 0$ & $77 / 2 / 1$ & $66 / 2 / 0$ & $10 / 1 / 0$ \\
\hline Major congenital malformation & 5 & 18 & 6 & 2 & 1 \\
\hline Jaundice requiring phototherapy & 55 & 175 & 212 & 293 & 99 \\
\hline Hypothermia & 0 & 1 & 1 & 8 & 4 \\
\hline Hypoglycemia & 6 & 6 & 5 & 4 & 1 \\
\hline Others & 36 & 45 & 55 & 77 & 25 \\
\hline
\end{tabular}


Table no. 3 Mortality profile

\begin{tabular}{|l|c|c|c|c|c|c|}
\hline & $\mathbf{2 0 1 5}$ & $\mathbf{2 0 1 6}$ & $\mathbf{2 0 1 7}$ & $\mathbf{2 0 1 8}$ & $\mathbf{2 0 1 9}$ (till may) & Total \\
\hline Respiratory distress syndrome & 3 & 1 & 1 & 0 & 0 & 5 \\
\hline Meconium aspiration syndrome & 1 & 0 & 0 & 1 & 0 & 2 \\
\hline HIE/Moderate-severe birth Asphyxia & 0 & 3 & 1 & 3 & 0 & 7 \\
\hline Sepsis/Pneumonia /Meningitis & 2 & 5 & 1 & 3 & 0 & 11 \\
\hline Major congenital malformation & 0 & 0 & 0 & 0 & 0 & 0 \\
\hline Prematurity & 1 & 0 & 4 & 3 & 0 & 8 \\
\hline Others & 5 & 1 & 0 & 1 & 0 & 7 \\
\hline Cause not established & 0 & 0 & 0 & 0 & 0 & 0 \\
\hline
\end{tabular}

\section{Discussion}

Data pertaining to disease pattern and mortality are useful for health care providers and policy makers to modify and plan treatment or interventions and evaluate the effectiveness of health care initiatives respectively. In our study out of total 1380 (75.2\%) were inbourn and 453 (24.7\%) were out born. This is comparable to the study by Rakesh Kumar et al., in $2019^{[8]}$. Similar to our study in studies by Baruah MN et al, Patil R et al, Rakholia $\mathrm{R}$ et al also the Significantly higher males were admitted in both inborn and out born groups $^{[9-11]}$. Gender bias as a cause for higher number of male admissions needs to be further evaluated.

In our study $580(31.6 \%)$ new bourns were pre term and 1256 (68.5\%) were term babies which is comparable to the studies by Rakholia $\mathrm{R}$ et al, and Modi $\mathrm{R}$ et $\mathrm{al}^{[11,12]}$. According to our study neonatal jaundice was found to be the most common cause of admission 834 (45.4\%), This is comparable to the study by Rakesh Kumar et al., Kotwal et al, Saini et al, and Prasad V et al ${ }^{[8,13-15]}$. Other prominent causes were sepsis 242 (13.2\%), birth asphyxia 125 (6.8\%), meconium aspiration syndrome 103 (5.6\%). The commonest causes of neonatal morbidity are similar across various studies.

Mortality rate in this study was 40 (2.18\%), Mortality rate reported varies between studies. This partly depends on the infrastructure of the treating facility. Mortality rate $16.9 \%$ NNPD $18.69 \%$ Prasad and $20.53 \%$ by Rakholia $\mathrm{R}$ et al $[11,13]$

In our study Most common reason for neonatal death was Sepsis/Pneumonia /Meningitis, 11 $(0.6 \%)$, other most common causes for neonatal death was prematurity $8(0.4 \%)$, HIE/Moderatesevere birth Asphyxia and others 7 (0.38\%).

Other studies have reported prematurity as the commonest cause of mortality, this may partly be because of the fact that premature babies needs more specialized care and owing to infrastructure lack they are being referred from our hospital to better equipped centers whenever the parents are willing. The major causes of mortality remain same across studies.

\section{Conclusion}

With advances in diagnostic and treatment modalities as well as government initiatives to decrease the neonatal mortality significant achievements have been made. The infant mortality rate and neonatal mortality rate which plays an important role in health planning, has shown a considerable decline, still much is left to be done. Our study shows that neonatal jaundice birth asphyxia and sepsis are the commonest causes of admission. Common causes of mortality were birth asphyxia and sepsis and prematurity. Most of the morbidities and subsequent mortalities can be prevented by developing infrastructure and training staff for providing effective neonatal resuscitation, practice hand hygiene for prevention of sepsis and effective implementation of IMNCI for early diagnosis of danger signs, timely intervention and timely referral to tertiary care centers.

\section{References}

1. The Department of Health and Human Service Control and Prevention. Racial/ethnic disparities in neonatal 
mortality- United State of America, 1995 2002. MMWR 2004; 54:553-558

2. Goodman DC, Fisher ES, Little GA. The relationship between the availability of neonatal intensive care unit and neonatal mortality. N Eng J Med, 2002;346:15381544.

3. Harrison KA. Child bearing, health and social priorities: A survey of 22,774 consecutive hospital births in Zaria, Northern. Nigeria. Br J Obestet Gynaecol. 1985:92:1-45.

4. Meme JS.A prospective study of neonatal death In Nairobi, Kenya. EAfr. Med J. 1978:262 7.

5. Orumabo RS, Okoji GO, Jacob OI. Care of newborn in Developing world: Report of afour-year Experience in Port Harcourt. Nig Med Prac. 1991; 22:59 64.

6. Dawodu AH, Effiong CE.Neonatal mortality and mortality Among Nigerian infants in a special care baby unit. E AfrMed J, 1983; 60:39 45.

7. Fazlur R, Amin J, Jan M, Hamid I.Pattern and outcome of admissions to neonatal unit of Khyber Teaching Hospital, Peshawar. Paki Med Sci. 2007;23 (2) :1-5.

8. Kumar R, Mundhra R, Jain A, Jain S. Morbidity and mortality profile of neonates admitted in special newborn care unit of a teaching hospital in Uttarakhand, India. Int J Res Med Sci 2019; 7:241-6.

9. Baruah MN, Panyang PP. Morbidity and mortality profile of newborns admitted to the special care newborn unit (SCNU) of a teaching hospital of upper Assam, India- a three year study. J Med SciClin Res. 2016 Aug;4(08):11689-95.

10. Patil R, Koppad R, Shreeshail B. Clinical profile and. outcome of babies admitted to Neonatal Intensive Care Unit (NICU), Mc Gann Teaching Hospital. Shivamogga, Karnataka: a longitudinal study. Sch J App Med Sci. 2014;2(6G):3357-60.
11. Rakholia R, Rawat V, Bano M, Singh G. Neonatal morbidity and mortality of sick newborns admitted in a teaching hospital of Uttarakhand. CHRISMED J Health Res. 2014 Oct 1;1(4):228.

12. Modi R, Modi B, Patel JK, Punitha KM. Study of the Morbidity and the Mortality Pattern in the Neonatal Intensive Care Unit at a Tertiary Care teaching Hospital in Gandhinagar District, Gujarat, India. J Res Med Den Sci. 2015;3(3):208-12.

13. Prasad V, Singh N. Causes of morbidity and mortality in neonates admitted in Government Medical College, Haldwani in Kumaun region (Uttarakhand) India. JPBS. 2011;8(8):1-4.

14. Kotwal YS, Yatoo GH, Ahmed Jan FA. Morbidity and mortality among neonates admitted to a neonatal intensive care unit of a tertiary care teaching hospital of Jammu and Kashmir (India). Neonat Pediatr Med. 2011;3:136.

15. Saini N, Chhabra S, Chhabra S, Garg L, Garg N. Pattern of neonatal morbidity and mortality: a prospective study in a district hospital in urban India. J ClinNeonatol. 2016 Jul 1;5(3):183-8. 